Check for updates

Cite this: RSC Adv., 2017, 7, 22479

\title{
Gold micromeshes as highly active electrocatalysts for methanol oxidation reaction $\uparrow$
}

\author{
Jingying Sun, $t^{a}$ Feng Wang, $t^{a}$ Y Yuan Liu, ${ }^{a}$ Yizhou Ni, ${ }^{a}$ Haiqing Zhou, ${ }^{a}$ Chuan Fei Guo*b \\ and Shuo Chen (D) *a
}

\begin{abstract}
A high density of surface defects is a key factor for efficient nanoscale gold ( $\mathrm{Au}$ ) electrocatalysts for the oxidation of small organic molecules. Here we present tunable pore size Au micromeshes with a high density of steps, kinks, twin boundaries, and stacking faults fabricated by using a template method. Electrocatalytic measurements on the methanol oxidation reaction show that the peak current density (normalized to the electrochemical surface area) of our Au mesh in alkaline electrolyte $(0.5 \mathrm{M} \mathrm{KOH}) \mathrm{can}$ reach $0.264 \mathrm{~mA} \mathrm{~cm}{ }^{-2}$, which is significantly higher than those of the well-studied nanoporous $\mathrm{Au}$ film $\left(0.081 \mathrm{~mA} \mathrm{~cm}{ }^{-2}\right)$ and nanoporous Au nanoparticles $\left(0.112 \mathrm{~mA} \mathrm{~cm}{ }^{-2}\right)$. Over $90 \%$ of the current density can be maintained after 500 cycling tests. Through transmission electron microscopy studies, the superior intrinsic activity and stability lie in the high linear density of surface defects, the exposure of active facets, and superficial tensile strain on the outter-most layers.
\end{abstract}

Received 28th February 2017 Accepted 17th April 2017

DOI: $10.1039 / c 7 r a 02505 j$

rsc.li/rsc-advances active sites due to their high surface energy, which promotes ionization and adsorption of intermediate reactants, such as $\mathrm{OH}^{-}$in electrolytes. ${ }^{\mathbf{1 3 , 1 4}}$ Therefore, precise control over the shape, size, and defect of Au nanostructures is the key to achieving excellent electrocatalytic activity.,15

Among different types of Au nanostructures (nanoparticles, nanowires, etc.), porous $\mathrm{Au}$ has attracted many interests because of their large surface area, high electrical conductivity, and frequent occurrences of low-coordination facets. ${ }^{8}$ The stateof-the-art porous Au films are usually fabricated by dealloying $\mathrm{Au}-\mathrm{Ag}$ or $\mathrm{Au}-\mathrm{Cu}$ alloys followed by thermal annealing. ${ }^{5,16}$ Although this approach is widely used, it fails to completely remove the residual $\mathrm{Ag}$ or $\mathrm{Cu}$, and thus can lead to a reduced catalytic activity compared to pure Au. ${ }^{17,18}$ Furthermore, the pore size formed by removing the sacrificial $\mathrm{Ag}$ or $\mathrm{Cu}$ components is from tens to hundreds of nanometers, ${ }^{9}$ which may block mass transport paths and reduce the effective surface area. ${ }^{19}$ Moreover, the dealloying approach mainly generates external surface defects such as steps and kinks. There is still plenty room to introduce dense and effective defects inside grains of porous $\mathrm{Au}$, such as stacking faults, dislocations, twins, etc.

Here we report a facile route to fabricate large-scale twodimensional (2D) pure $\mathrm{Au}$ micromeshes with tunable pore size by using a template method. The 2D Au nanostructures with micrometer pores can effectively utilize the catalyst surface.$^{10}$ Through our materials, intrinsic catalytic activities of $\mathrm{Au}$ are investigated, which are superior to that of dealloyed Au. ${ }^{\mathbf{1 6}}$ The high activity of Au micromeshes is attributed to high-index surfaces and defects inside grains that are required to accommodate the porous structure of the micromeshes, which are

\footnotetext{
${ }^{a}$ Department of Physics \& The Texas Center for Superconductivity, University of Houston, Houston, Texas 77204, USA. E-mail: schen34@uh.edu Technology of China, Shenzhen, Guangdong 518055, China. E-mail: guocf@sustc. edu.cn

$\dagger$ Electronic supplementary information (ESI) available: CV curves with different scan rate, SEM images of morphology change before and after cycling, TEM images of surface atomic structures, and comparison of electro-oxidation activity among Au nanostructures. See DOI: 10.1039/c7ra02505j

\$ J. S., and F. W. contributed equally.
}

\footnotetext{
modate the porous structure of the micromeshes, which are
} 
confirmed by our high-resolution transmission electron microscopy (HRTEM) observation. In addition, our Au micromesh exhibits good stability: it remains $90 \%$ of activity even after 500 cycles, which is far better than reported results.

\section{Experimental}

\section{Au micromeshes fabrication}

The micromeshes were fabricated via a template method. First, poly(methyl methacrylate) (PMMA) porous film template was prepared via a phase separation method induced by nonsolvent (water). ${ }^{20}$ A glass slide was dipped into the mixture of tetrahydrofuran (THF)/water/PMMA (mass ratio $25: 2.5: 1$ ) and subsequently dried at $75{ }^{\circ} \mathrm{C}$ for $15 \mathrm{~min}$. A sacrificial layer of $\mathrm{SiO}_{2}$ $(60 \mathrm{~nm})$ and a layer of Au $(50 \mathrm{~nm})$ were deposited successively onto the template by an electron beam evaporation system (Edwards BOC-500). The sacrificial silica layer was dissolved by wedging the glass slide into $\mathrm{HF}$ to obtain $\mathrm{Au}$ micromeshes ${ }^{21}$ (Fig. 1). To characterize the electrocatalytic performance, the micromeshes were transferred to electrochemically inert polydimethylsiloxane (PDMS) substrates. ${ }^{22}$ For TEM studies, the Au micromeshes were loaded to copper TEM grids coated with holy carbon films.

\section{Structural characterization}

The morphologies of $\mathrm{Au}$ micromeshes were characterized by a field-emission scanning electron microscope (FE-SEM, LEO 1512). The surface facets and defects were studied with a highresolution transmission electron microscope (HRTEM, JEOL 2010F).

\section{X-ray photoelectron spectroscopy}

The binding energies of $4 \mathrm{f}$ orbit of Au micromeshes and Au film were explored by X-ray photoelectron spectroscopy (XPS, Electronics Model 5700). The data were obtained over a binding energy range of 80-100 eV with the energy increment of $0.1 \mathrm{eV}$. Each spectrum was averaged by three scans and each peak was

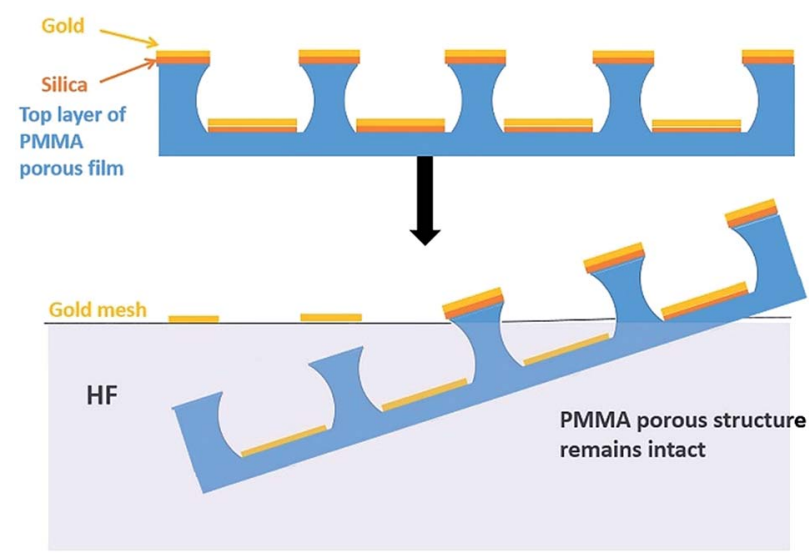

Fig. 1 Schematic process of lifting Au micromeshes from porous template. base-line corrected by the carbon 1s spectra whose peak energy is $284.5 \mathrm{eV}$.

\section{Electrochemical measurements}

The electrochemical activity of $\mathrm{Au}$ micromeshes for MOR was obtained in a standard three-electrode system consisted of a $\mathrm{Au}$ micromeshes/PDMS working electrode, a Pt wire counter electrode, and a saturated calomel reference electrode (SCE) in acidic electrolyte or a mercury oxide mercury $(\mathrm{Hg} / \mathrm{HgO})$ reference electrode in alkaline environment. All the electrochemical performances of $\mathrm{Au}$ micromeshes were conducted using an electrochemical workstation (Biologic SP-200) at room temperature $\left(25{ }^{\circ} \mathrm{C}\right)$. All the potentials presented in the paper were converted to the reversible hydrogen electrode (RHE) scale.

\section{Measurement of electrochemical active surface area (ECSA)}

Prior to MOR in alkaline solution, the $\mathrm{Au}$ micromeshes were cleaned in Ar-saturated $0.1 \mathrm{M} \mathrm{HClO}_{4}$ solution with a scan rate of $20 \mathrm{mV} \mathrm{s}^{-1}$ from $0.65 \mathrm{~V}$ to $1.6 \mathrm{~V}$ for 30 cycles. The electrochemical active surface area (ECSA) of Au micromeshes working electrodes were calculated by:

$$
\mathrm{ECSA}=\frac{Q}{a \cdot v}=\frac{\int I \mathrm{~d} U}{a \cdot v}
$$

where $Q$ is the charge related to the reduction of AuO layer; $I$ and $U$ are the current and voltage in the $\mathrm{CV}$ curves around the $\mathrm{AuO}$ striping peak at $1.2 \mathrm{~V}$, respectively; $v$ is the scanning rate; $a$ is the charge per unit area of $\mathrm{Au}\left(400 \mu \mathrm{C} \mathrm{cm}^{-2}\right) .{ }^{23,24}$ The activities of $\mathrm{Au}$ micromeshes for MOR were measured by cyclic voltammetry (CV) in an Ar-saturated mixed solution of $0.5 \mathrm{M} \mathrm{KOH}$ and $1 \mathrm{M}$ $\mathrm{CH}_{3} \mathrm{OH}$, in the potential range 0.85 to $1.6 \mathrm{~V}$ at the scan rate of $20 \mathrm{mV} \mathrm{s}^{-1}$. The specific activities were normalized by ECSA.
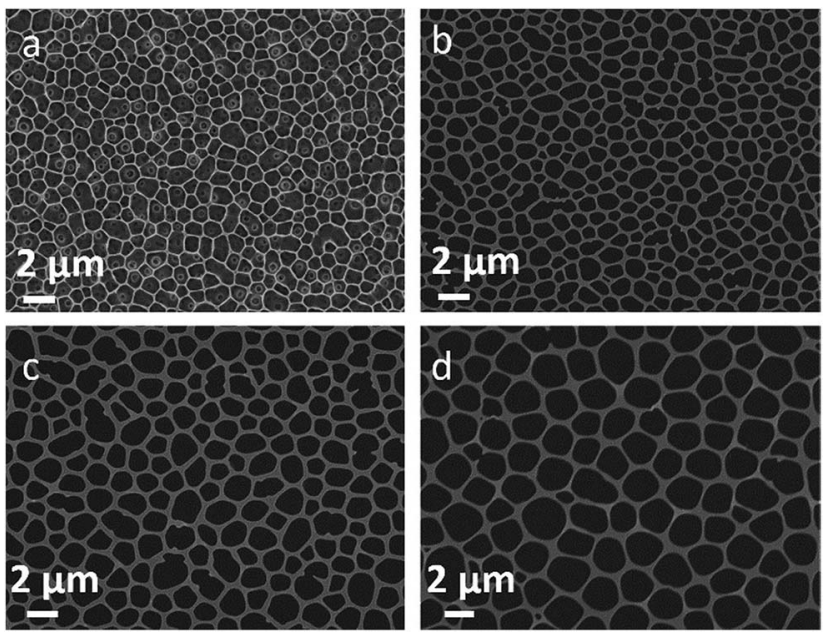

Fig. 2 SEM images of (a) the PMMA template with a pore size of $1 \mu \mathrm{m}$ and (b) corresponding Au micromeshes. As templates can control pore sizes of Au micromeshes, Au micromeshes with an average pore size of (c) $1.5 \mu \mathrm{m}$ and (d) $2 \mu \mathrm{m}$ were further produced using the same method. 


\section{Results and discussions}

The as-fabricated $\mathrm{Au}$ micromeshes typically have a geometric area of $1.5 \mathrm{~cm}^{2}(1 \mathrm{~cm} \times 1.5 \mathrm{~cm})$. Fig. 2 shows some representative SEM images of the as-fabricated $\mathrm{Au}$ micromeshes. The Au micromeshes consist of uniform porous structure, which is analogous to the $2 \mathrm{D} \mathrm{Au}$ nanoporous films made by the dealloying method. ${ }^{16}$ In addition, the average pore sizes of $\mathrm{Au}$ micromeshes are controlled by the pore sizes of the PMMA template (Fig. 2a) which can further be tuned by changing the PMMA/water ratio. As shown in Fig. 2b-d, with the PMMA concentration being $10 \%, 8 \%$, and $7 \%$, the corresponding average pore diameters $\left(D_{\mathrm{n}}\right)$ are $\sim 1( \pm 0.3) \mu \mathrm{m}$, $\sim 1.5( \pm 0.5) \mu \mathrm{m}$, and $\sim 2( \pm 0.6) \mu \mathrm{m}$. The samples are subsequently named as Am-1, Am-1.5, and Am-2, respectively. The energy-dispersive X-ray spectroscopy (EDS) mapping results indicate that carbon is distributed on the whole SEM image of PMMA template, and Au forms the mesh structure with various pore sizes (Fig. S1 and insets $\dagger$ ).

Fig. 3a shows the $\mathrm{CV}$ curves of $\mathrm{Au}$ micromeshes with different pore sizes in $0.1 \mathrm{M} \mathrm{HClO}_{4}$ solution at a scan rate of $20 \mathrm{mV} \mathrm{s}^{-1}$, from which the ECSA is calculated as $0.606 \mathrm{~cm}^{2}$, $0.348 \mathrm{~cm}^{2}$, and $0.313 \mathrm{~cm}^{2}$ for Am-1, Am-1.5, and Am-2, respectively. The specific activity of Au micromeshes on MOR in $0.5 \mathrm{M}$ $\mathrm{KOH}$ and $1 \mathrm{M} \mathrm{CH}_{3} \mathrm{OH}$ electrolyte is shown in Fig. 3b. Am-1 has the highest activity with the highest peak current density of $0.336 \mathrm{~mA} \mathrm{~cm}{ }^{-2}$, followed by Am-1.5 with $0.280 \mathrm{~mA} \mathrm{~cm}^{-2}$ and Am-2 with $0.221 \mathrm{~mA} \mathrm{~cm}^{-2}$. Fig. $3 \mathrm{c}$ shows the $\mathrm{CV}$ curves from 0.85 to $1.6 \mathrm{~V}$ in the alkaline solution with and without methanol of the sample Am-1. In the solution with methanol, the current density reaches a stable maximum of $0.336 \mathrm{~mA} \mathrm{~cm}^{-2}$ at the potential of $1.27 \mathrm{~V}$ after several cycles. However, there is no peak observed in the methanol free solution at the same potential.

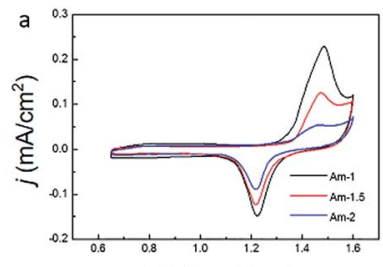

E (V vs. RHE)

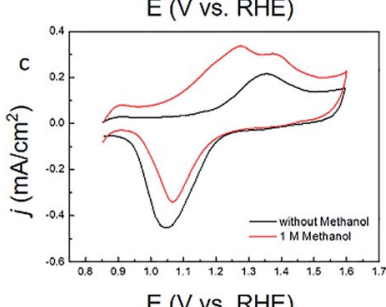

E (V vs. RHE)

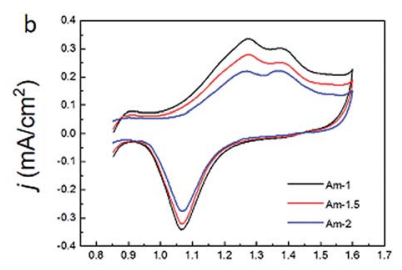

E (V vs. RHE)

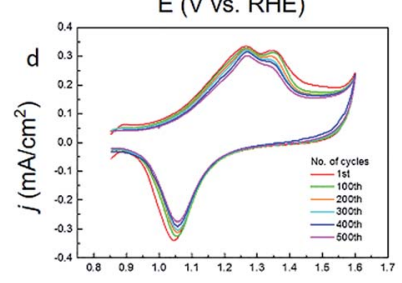

E (V vs. RHE)
Fig. 3 Electrochemical performances of Au micromeshes sample. (a) Oxide stripping curves of Au micromeshes with different pore sizes in $0.1 \mathrm{M} \mathrm{HClO}_{4}$ solution. (b) Catalytic methanol electro-oxidation measurements on Am-1, Am-1.5, and Am-2 samples in $0.5 \mathrm{M} \mathrm{KOH}+$ $1 \mathrm{M} \mathrm{CH}_{3} \mathrm{OH}$ solution. (c) CVs of Am-1 electrode on in $0.5 \mathrm{M} \mathrm{KOH}$ with and without $1 \mathrm{M} \mathrm{CH}_{3} \mathrm{OH}$ solution. (d) Repetitive potential cycling in $0.5 \mathrm{M} \mathrm{KOH}+1 \mathrm{M} \mathrm{CH}_{3} \mathrm{OH}$ on Au micromeshes sample with Am-1. The scan rate is $20 \mathrm{mV} \mathrm{s}^{-1}$.
On the other hand, one smaller peak is observed at $1.37 \mathrm{~V}$ in both solutions with/without methanol. Comparing these two CV curves, we conclude that the first oxidation peak at $1.27 \mathrm{~V}$ is from the MOR, and the hump located at $1.37 \mathrm{~V}$ is associated with $\mathrm{Au}$ surface oxidation. ${ }^{7}$ The Au oxides are subsequently removed during the negative sweeping scan, yield a reduced peak at $1.05 \mathrm{~V}^{25}$ We further confirm the methanol oxidation reaction on the $\mathrm{Au}$ micromeshes with different methanol concentrations and various scanning rates in $0.5 \mathrm{M} \mathrm{KOH}$ medium. In the typical CVs (Fig. S2a $\dagger$ ) taken from various methanol concentrations in $0.5 \mathrm{M} \mathrm{KOH}$ on $\mathrm{Am}-1$, the current density increases linearly from $0.275 \mathrm{~mA} \mathrm{~cm}^{-2}$ to $0.510 \mathrm{~mA}$ $\mathrm{cm}^{-2}$ (Fig. S2b $\dagger$ ) with methanol concentration increasing from $0.5 \mathrm{M}$ to $3.0 \mathrm{M}$. In addition, the higher the methanol concentration, the more negative is the MOR peak position. Fig. S2c and $\mathrm{d} \dagger$ show the $\mathrm{CV}$ curves of Am-1 in $0.5 \mathrm{M} \mathrm{KOH}$ and $1 \mathrm{M}$ $\mathrm{CH}_{3} \mathrm{OH}$ with different scan rates. Without changing the peak position, the peak current densities increase with the scan rates. An oxidation peak appeared at $1.01 \mathrm{~V}$ on the back scanning curve with the scan rate of $5 \mathrm{mV} \mathrm{s}^{-1}$, indicating a continuous methanol oxidation reaction. We also executed MOR experiments on Am-1 in 1.0 M methanol with different $\mathrm{KOH}$ concentrations from $0.1 \mathrm{M}$ to $2 \mathrm{M}$. (Fig. S3†) The peak current also displays an increase in proportion to the $\mathrm{KOH}$ concentration, boosting from $0.312 \mathrm{~mA} \mathrm{~cm}^{-2}$ to $0.641 \mathrm{~mA} \mathrm{~cm}^{-2}$, and the peak position eventually negatively shifts to $1.22 \mathrm{mV}$ in $2.0 \mathrm{M}$ $\mathrm{KOH}$. The peak shift can be attributed to the improved catalytic activity by increasing the coverage of $\mathrm{OH}^{-}$on the electrode at higher $\mathrm{KOH}$ concentrations. ${ }^{26}$ In order to compare our results with literature values, we extract the activity from CV curves with the scan rate of $20 \mathrm{mV} \mathrm{s}^{-1}$ in the $0.5 \mathrm{M} \mathrm{KOH}$ with $1 \mathrm{M} \mathrm{CH}_{3} \mathrm{OH}$ solution. Subtracting the background current in the methanolfree electrolyte, the peak current densities increase from 0.149 $\mathrm{mA} \mathrm{cm}{ }^{-2}$ to $0.208 \mathrm{~mA} \mathrm{~cm}{ }^{-2}$ with average pore size decreasing from $\sim 2 \mu \mathrm{m}$ to $\sim 1.5 \mu \mathrm{m}$. Furthermore, when the average pore size decreases from $\sim 2 \mu \mathrm{m}$ to $\sim 1 \mu \mathrm{m}$, the peak current density increases from $0.208 \mathrm{~mA} \mathrm{~cm}^{-2}$ to $0.264 \mathrm{~mA} \mathrm{~cm}^{-2}$. The electrocatalytic activities (subtracting background) of Au with different morphologies in literatures are compared in Table S1. $\dagger$ The MOR current density of our Am-1 sample $\left(0.264 \mathrm{~mA} \mathrm{~cm}{ }^{-2}\right)$ is significantly higher than those of all existing Au nanostructures including the trisoctahedron Au nanocrystals $\left(0.139 \mathrm{~mA} \mathrm{~cm}^{-2}\right)$, the hollow nanoporous $\mathrm{Au}$ nanoparticles $\left(0.112 \mathrm{~mA} \mathrm{~cm}^{-2}\right)$, the nanoporous $\mathrm{Au}\left(0.081 \mathrm{~mA} \mathrm{~cm}{ }^{-2}\right)$, etc. The onset potentials at which the current density reaches $0.01 \mathrm{~mA} \mathrm{~cm}^{-2}$ are also presented in Table S1.† The Au micromeshes achieve the lowest MOR onset/peak potential $(V)$ among all $\mathrm{Au}$ nanostructure catalysts.

Next, we discuss the mechanism of high intrinsic activity of our Au micromeshes. In alkaline solution, methanol is oxidized to $\mathrm{HCOO}^{-}$by $\mathrm{OH}^{-}$chemisorbed onto the surface of the nanostructured $\mathrm{Au}$ with transferring of four electrons at relatively lower potentials ( 0.85 to $1.45 \mathrm{~V}$ ) and oxidized to $\mathrm{CO}_{3}{ }^{2-}$ by $\mathrm{OH}^{-}$ with transferring of six electrons at higher potentials (above $1.45 \mathrm{~V}) .{ }^{6}$ However, the intrinsic adsorption ability on $\mathrm{Au}$ is weak, resulting in a low-concentration of chemisorbed $\mathrm{OH}^{-}$anions on the surface and thus a relatively low electrocatalytic activity. ${ }^{6,17,27}$ 
As pointed out by first-principle calculations, the adsorption is closely related to the d-band filling of transition metal catalysts. ${ }^{28}$ Higher d-band centre yields less occupation of antibonding state and thus enhances the chemisorption strength (d-band centre theory). ${ }^{29,30}$ In our samples, both tensile strain and low-coordinated $\mathrm{Au}$ atoms will cause reduction in the overlap of electron cloud of d-band, consequently narrow the $\mathrm{Au}$ d-band and upshift the d-band centre. ${ }^{31}$ Our XPS results of regular Au film, Am-1, Am-1.5, and Am-2 (Fig. S4†) further confirm the upshift of d-band centre. XPS is much more sensitive to the $\mathrm{Au}$ 4f signals than to the Au $5 \mathrm{~d}$ signals, and the binding energy of $\mathrm{d}$ band and $4 \mathrm{f}$ core line of $\mathrm{Au}$ is correlated, although the absolute values of them differ. ${ }^{32}$ So here we use the shift of $\mathrm{Au} 4 \mathrm{f}$ peaks to represent that of Au 5d signals. Our XPS results indicate that the $4 \mathrm{f}$ peaks of $\mathrm{Au}$ micromeshes samples Am-1, Am-1.5, and Am-2 all have lower binding energy compared with that of $\mathrm{Au}$ film. Consequently, the d centres of our Au micromeshes are higher than that of the Au film. Among the three Au micromeshes samples, AM-1 shows the lowest $4 \mathrm{f}$ binding energy, indicating a highest $d$ band centre, although the shift is not significant. Such a small change can be attributed to a relatively low contribution of surface facets and strains to the core $4 \mathrm{f}$ energy.

To understand the electrocatalytic performance of $\mathrm{Au}$ micromeshes, it is essential to characterize their surface morphology. TEM image (Fig. 4a) indicates that the micromeshes consist of grains with 10 to $50 \mathrm{~nm}$ diameter. A typical
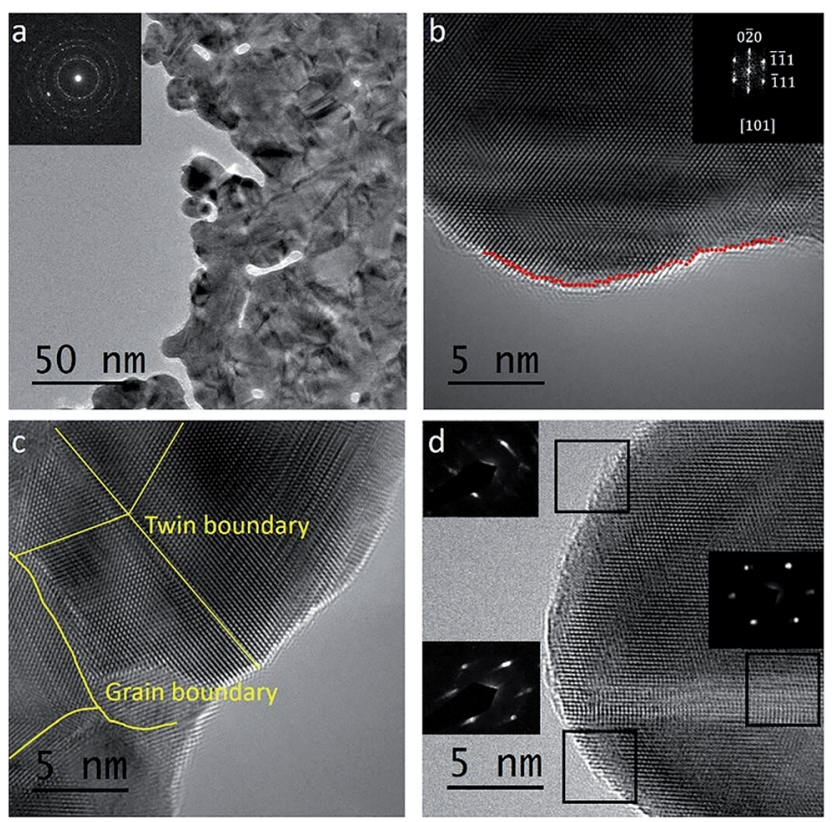

Fig. 4 Surface atomic structure of Au micromeshes sample. (a) Low magnification TEM image of Au micromeshes. The diffraction pattern (inset) shows that the Au micromeshes are polycrystalline. Typical Au micromeshes HRTEM image and FFT results (inset). (b) High-index planes appear on the surface area, and (c) grain boundary, twin boundary, stacking faults, steps and kinks are observed. (d) Nanobeam electron diffraction (NBD) patterns on two surfaces. Viewing along the [101] zone axis, the elongate spots are perpendicular to the local surface plan. high-resolution TEM image (Fig. 4b) reveals the abundance of surface steps, dislocations, twin boundaries, and stacking faults (Fig. 4c). In general, for face centre cubic $\mathrm{Au}$, planes with higher surface energy are more catalytic active. ${ }^{13,33}$ For example, the 110 (ref. 21) surfaces have higher surface energy $\left(1.94 \mathrm{~J} \mathrm{~m}^{-2}\right)$ than the 100 and 111 (ref. 34 ) surfaces $\left(1.80 \mathrm{~J} \mathrm{~m}^{-2}\right.$ and $1.52 \mathrm{~J} \mathrm{~m}^{-2}$, respectively), and also higher catalytic MOR activity. ${ }^{\mathbf{8 , 3 5}, 36}$ The mechanism can be attributed to the stronger adsorptions of intermediate reaction species, such as $\mathrm{OH}_{\mathrm{ad}}^{-}$, and $\mathrm{Au}-$ $\mathrm{OH}_{\mathrm{ads}}^{(1-\lambda)-}$. For stacking faults and dislocations, the atoms in their vicinities have high surface energies, therefore serve as active sites provided that they locate on the out-most atoms layers. ${ }^{37}$ In addition, the twin boundaries are also active sites because the atoms in the boundaries possess low-coordination numbers comparing with the internal and close packed atoms. ${ }^{38}$

We also carried out detailed analysis of the surface steps, the most abundant features on our Au micromeshes. A statistical analysis is performed over 1000 steps among 150 HRTEM images to quantify the linear density of defects on the $\mathrm{Au}$ micromeshes of different planes along the pore perimeter projected along [101] zone axis. Three representative HRTEM images are shown in Fig. $\mathrm{S} 5 \dagger$. As a result, the low-index facets, such as (100) and (111), and other defects are frequently observed in all the images. The total number of high-index facets increases significantly with the decreasing pore size. As shown in Fig. S5 $\uparrow$ the corresponding linear density of highindex facets increases from $0.67 \mathrm{~nm}^{-1}, 0.81 \mathrm{~nm}^{-1}$ to 1.04 $\mathrm{nm}^{-1}$ with pore size decreasing from $2 \mu \mathrm{m}, 1.5 \mu \mathrm{m}$ to $1 \mu \mathrm{m}$, respectively. The enhanced activity for MOR on Au micromeshes with smaller pore sizes can be attributed to preferential adsorption of $\mathrm{OH}_{\mathrm{ad}}^{-}$, and $\mathrm{Au}-\mathrm{OH}_{\mathrm{ads}}^{(1-\lambda)-}$ on higher fractions of high-index facets. ${ }^{6}$ The linear density of steps on Am-1 is 1.04 $\mathrm{nm}^{-1}$, which is much higher than $0.59 \mathrm{~nm}^{-1}$ on the best reported nanoporous $\mathrm{Au},{ }^{8}$ and such a high density of steps is critical to the high performance of our Au meshes.

As we have introduced, based on the "d-band centre theory", tensile strain on $\mathrm{Au}$ can enhance the surface adsorption and improve the electrocatalytic activity of Au. ${ }^{8,11,39}$ In a reported TEM study on nanoporous $\mathrm{Au}$, an out-of-plane tensile strain is observed by nanobeam electron diffraction (NBD). ${ }^{8}$ The authors attributed the excellent MOR performance of their nanoporous $\mathrm{Au}$ to the tensile strain. ${ }^{8}$ Here we also performed NBD on the edge and centre of our $\mathrm{Au}$ micromeshes and observed the outof-plane tensile strain. As shown in Fig. 4d, the tensile strain on local surface planes is indicated by the elongated NBD spots perpendicular to their local surface planes. In contrast, the NBD pattern from the centre part of the micromeshes does not show streaked spots, which means that no tensile strain exists in the interior of $\mathrm{Au}$ micromeshes. This is reasonable, because the middle part of strips is often a neutral plane even if a structure is highly deformed.

The stability of our most active sample, Am-1, is shown in Fig. $3 \mathrm{~d}$, where $90 \%$ of the activity still retains after 500 cycles between $0.85 \mathrm{~V}$ to $1.6 \mathrm{~V}$ because of the retention of steps, kinks, twins, stacking faults, and dislocations in $\mathrm{Au}$ micromeshes (Fig. S6a and $\mathrm{b}_{\dagger} \dagger$ ). The stability is much better than those of 
other reported nanostructured $\mathrm{Au}$, such as nanoporous $\mathrm{Au}$ nanoparticles with $150 \mathrm{~nm}$ particle sizes, whose peak current density decreases to $64 \%$ after 480 cycles. ${ }^{5}$ The number density of steps, kinks, twins, stacking faults, and dislocations in cycled $\mathrm{Au}$ micromeshes is reduced to $0.97 \mathrm{~nm}^{-1}$, which is due to the increased radius of curvatures on the surface of $\mathrm{Au}$ micromeshes after cycling (Fig. S6c and $d \dagger$ ).

\section{Conclusions}

In summary, we have developed a template method to fabricate large area 2D Au micromeshes. The Au micromeshes with pore diameters of 1 to $2 \mu \mathrm{m}$ are studied. The MOR electrocatalytic activity, with a peak density of $0.264 \mathrm{~mA} \mathrm{~cm}{ }^{-2}$ and an onset potential of $0.85 \mathrm{~V}$, is among the best in Au electrocatalysts. Over $90 \%$ of the activity still retains after 500 cycles between 0.85 and $1.6 \mathrm{~V}$. Under TEM, we characterized high density surface defects, such as steps, kinks, twins, stacking faults, and dislocations, and found that the on-edge high-index facets with low-coordination number located on the surface defects may be responsible for the high electrocatalytic performance. By quantifying the high density of steps and kinks on the exposed surfaces of $\mathrm{Au}$ micromeshes, the highest linear density of the steps and kinks is $\sim 1.04 \mathrm{~nm}^{-1}$ in Au micromeshes with a pore size of $1 \mu \mathrm{m}$, which is significantly higher than that in nanoporous Au. The tensile strain caused by the edge effect applied on the out-most atomic layers could also enhance the absorbability of intermediates and the activity. Our method of fabricating micromesh structure offers a new way to design other $2 \mathrm{D}$ micromeshes polycrystalline metals for various electrode applications.

\section{Acknowledgements}

J. S. and S. C. acknowledge the support from TcSUH as the TcSUH Robert A. Welch Professorships in High Temperature Superconducting (HTSg) and Chemical Materials (E-0001). The work performed at SUSTC was supported by the funding of "The Recruitment Program of Global Youth Experts of China" (No. K16251101), the National Natural Science Foundation of China (No. U1613204), and the advance funding of the "Peacock Plan" (No. Y01256120). We also thank Dr Wenchao Sheng at Columbia University for her fruitful discussion.

\section{References}

1 C.-J. Zhong and M. M. Maye, Adv. Mater., 2001, 13, 15071511.

2 L. D. Burke and P. F. Nugent, Gold Bull., 1998, 31, 39-50.

3 J. E. Bailie and G. J. Hutchings, Chem. Commun., 1999, 21512152.

4 C. F. Guo, T. Sun, Q. Liu, Z. Suo and Z. Ren, Nat. Commun., 2014, 5, 3121.

5 S. Pedireddy, H. K. Lee, W. W. Tjiu, I. Y. Phang, H. R. Tan, S. Q. Chua, C. Troadec and X. Y. Ling, Nat. Commun., 2014, $5,4947$.
6 J. Zhang, P. Liu, H. Ma and Y. Ding, J. Phys. Chem. C, 2007, 111, 10382-10388.

7 Y. Song, T. Miao, P. Zhang, C. Bi, H. Xia, D. Wang and X. Tao, Nanoscale, 2015, 7, 8405-8415.

8 T. Fujita, P. Guan, K. McKenna, X. Lang, A. Hirata, L. Zhang, T. Tokunaga, S. Arai, Y. Yamamoto, N. Tanaka, Y. Ishikawa, N. Asao, Y. Yamamoto, J. Erlebacher and M. Chen, Nat. Mater., 2012, 11, 775-780.

9 Y. Ding and Z. Zhang, in Springer Handbook of Nanomaterials, ed. R. Vajtai, Springer, Verlag Berlin Heidelberg, 2013, vol. 1, pp. 779-818.

10 L. H. Qian and M. W. Chen, Appl. Phys. Lett., 2007, 91, 083105.

11 C. Bi, C. Feng, T. Miao, Y. Song, D. Wang and H. Xia, Nanoscale, 2015, 7, 20105-20116.

12 W. Wang, J. Zhang, S. Yang, B. Ding and X. Song, ChemSusChem, 2013, 6, 1945-1951.

13 Z. Quan, Y. Wang and J. Fang, Acc. Chem. Res., 2013, 46, 191202.

14 J. Lai, W. Niu, R. Luque and G. Xu, Nano Today, 2015, 10, 240-267.

15 F.-S. Ke, B. Solomon, Y. Ding, G.-L. Xu, S.-G. Sun, Z. L. Wang and X.-D. Zhou, Nano Energy, 2014, 7, 179-188.

16 H. Xia, Y. Ran, H. Z. Li, X. Tao and D. Wang, J. Mater. Chem. $A, 2013,1,4678$.

17 A. Wittstock, V. Zielasek, J. Biener, C. M. Friend and M. Baumer, Science, 2010, 327, 319-322.

18 Y. Ding and M. Chen, MRS Bull., 2009, 34, 569-576.

19 A. Wittstock, J. Biener and M. Baumer, Phys. Chem. Chem. Phys., 2010, 12, 12919-12930.

20 Y. Wang, Z. Liu, Y. Huang, B. Han and G. Yang, Langmuir, 2006, 22, 1928-1931.

21 C. F. Guo, Y. Lan, T. Sun and Z. Ren, Nano Energy, 2014, 8, 110-117.

22 C. F. Guo, Y. Chen, L. Tang, F. Wang and Z. Ren, Nano Lett., 2016, 16, 594-600.

23 K. A. Friedrich, F. Henglein, U. Stimming and W. Unkauf, Colloids Surf., A, 1998, 134, 193-206.

24 S. Xiao, F. Xiao, Y. Hu, S. Yuan, S. Wang, L. Qian and Y. Liu, Sci. Rep., 2014, 4, 4370.

25 K. A. Assiongbon and D. Roy, Surf. Sci., 2005, 594, 99-119.

26 S. Koçak, Z. Dursun and F. N. Ertaș, Turk. J. Chem., 2011, 35, 711-722.

27 C. Yu, F. Jia, Z. Ai and L. Zhang, Chem. Mater., 2007, 19, 6065-6067.

28 A. Nilsson, L. G. M. Pettersson, B. Hammer, T. Bligaard, C. H. Christensen and J. K. Nørskov, Catal. Lett., 2005, 100, 111-114.

29 N. Lopez, T. V. W. Janssens, B. S. Clausen, Y. Xu, M. Mavrikakis, T. Bligaard and J. K. Nørskov, J. Catal., 2004, 223, 232-235.

30 B. Hammer and J. K. Nørskov, Surf. Sci., 1995, 343, 211-220. 31 S. Schnur and A. Groß, Phys. Rev. B: Condens. Matter Mater. Phys., 2010, 81, 033402.

32 P. H. Citrin, G. K. Wertheim and Y. Baer, Phys. Rev. B: Condens. Matter Mater. Phys., 1983, 27, 3160. 
33 C.-Y. Chiu, P.-J. Chung, K.-U. Lao, C.-W. Liao and M. H. Huang, J. Phys. Chem. C, 2012, 116, 23757-23763.

34 C. Badan, M. T. M. Koper and L. B. F. Juurlink, J. Phys. Chem. C, 2015, 119, 13551-13560.

35 Q. Zhang and H. Wang, ACS Catal., 2014, 4, 4027-4033.

36 J. Hernández, J. Solla-Gullón, E. Herrero, A. Aldaz and J. M. Feliu, Electrochim. Acta, 2006, 52, 1662-1669.
37 J. A. Zimmerman, C. L. Kelchner, P. A. Klein, J. C. Hamilton and S. M. Foiles, Phys. Rev. Lett., 2001, 87, 165507.

38 Y. Lu, J.-p. Tu, C.-d. Gu, X.-h. Xia, X.-l. Wang and S. X. Mao, J. Mater. Chem., 2011, 21, 4843.

39 S. Xie, S. I. Choi, N. Lu, L. T. Roling, J. A. Herron, L. Zhang, J. Park, J. Wang, M. J. Kim, Z. Xie, M. Mavrikakis and Y. Xia, Nano Lett., 2014, 14, 3570-3576. 